\title{
Do verso ao vão: aspectos da negação em "O rei menos o reino" e "Não", de Augusto de Campos
}

Resumo: Augusto de Campos é uma das vozes mais longevas da literatura brasileira. Em seus mais de setenta anos de atividade poética produziu livros, objetos, móbiles, hologramas e esculturas. Desde o início dos anos 1950, Augusto persegue uma espécie de negação do poético, que aqui entendemos como propositiva. $\mathrm{O}$ "não" em Campos pode ser visto como a espinha dorsal que reúne sua obra. Assim, propomos a leitura de dois poemas do autor: "O rei menos o reino" e o livro-xerox "Não", a fim de compreender como a negatividade se desdobra do verso à sua realidade material.

Palavras-chave: Augusto de Campos, poesia concreta, "O rei menos o reino"

Abstract: Augusto de Campos is one of the most long-lived voices in Brazilian literature. In more than seventy years of poetic activity he produced books, objects, mobiles, holograms and sculptures. Since the early 1950s, Augusto has pursued a kind of negacion of the poetic, which we understand as propositional. The "no" in Campos can be seen as the backbone that brings together his work. Thus, we propose the reading of two poems by the author, "O rei menos o reino" and the photocopy book "Não" in order to understand how the negativity unfolds from the verse to its material reality.

Keywords: Augusto de Campos, concrete poetry, "O rei menos o reino"

Onde a angústia roendo um não de pedra Augusto de Campos

É diante do "não" que o poeta começa sua jornada. Em “O rei menos o reino", publicado em livro homônimo, em 1951, a palavra "não" faz referência não somente àquilo que se tornará programa da poesia de Augusto de Campos, mas se refere sobretudo à forma múltipla em que a negatividade e a recusa aparecem em sua obra.

Partir deste princípio é buscar reconhecer na obra de Campos os contornos de uma margem (rumo ao precipício ${ }^{1}$ ) que apresenta alguma linearidade temática, marcada pela 
própria produção poética, mas também pela escolha dos elementos materiais que comporão seus poemas e livros.

Saltando de 1951 a 1990, através da análise de dois poemas do autor, "O rei menos o reino" e o livro-xerox Não, pretendemos aqui, mesmo que com uma lacuna temporal tão acentuada, estabelecer relações entre os poemas, a fim de pontuar a obsessão pelas formas negativas (inclusive materiais) da poesia e entender como elas se estabelecem e avançam, dentro da uma visão geral da teoria da Poesia Concreta, que está explícita na obra de Augusto de Campos.

Assim, passaremos tanto pela análise poética quanto por uma breve contextualização das formas de produção dos poemas e suas implicações éticas e históricas - aspectos que não devem ser negligenciados, principalmente no que se refere à produção dos poetas concretos - na medida que isso se mostrar relevante.

Levando em consideração que "O rei menos o reino" apresenta versos lineares e é estruturado em estrofes, ${ }^{2}$ a leitura que proporemos será mais voltada à composição logopeica, ${ }^{3}$ deslizando, por óbvio, para seus aspectos sonoros e visuais. Tendo em conta o signo verbivocovisual, nos apoiaremos naquilo que é primário - de uma poesia ainda por vir, em formação - e também nas outras vozes que compõem o poema, como referências à tradição poética.

Já na análise de "Não", avançaremos ao aspecto vida/obra de Augusto de Campos e do movimento da poesia concreta para compreender a forma não só poética, mas histórico-política, de uma manifestação de negação, negatividade. Em razão do salto temporal, fez-se necessário contextualizar como a poesia de Augusto de Campos desenvolveu-se tanto em relação à sua recepção e circulação quanto à sua produção poética e de livros. $\mathrm{E}$, como pretendemos mostrar aqui, o quanto sua poesia estava materialmente e sígnicamente relacionada às formas do não.

\section{Um não de pedra}

Sob a angústia que abre o primeiro verso de "O rei menos o reino", o leitor experimentará a geografia desértica de uma paisagem externa e interna ao poema. o "duro reino" que o eu poético enfrenta se manifesta em uma fala que busca lapidar a pedra para encontrar a "arena areia", com uma "voz que esconde outra", em um canto "que é antes desencanto".

Interessante que o poema, dividido em sete partes, usa o canto (tal qual Pound e os provençais) em um movimento que sugere uma captura de si por um eu que é o outro, mas que está entre os próprios dedos. As "dobras", como sugere o eu poético, vão sendo desmanchadas, como um drapeado que mostra uma face e esconde a outra. Ora, o que está por detrás do canto que o eu poético sabe de onde vem, mas não ouve ouvir?

Por isso minha voz esconde outra

Que em suas dobras desenvolve outra 
Onde em forma de som perdeu-se o Canto

Que eu sei aonde mas não ouço ouvir

(Campos 1986: 9)

Sterzi (2011: 15), ao comparar "O rei menos o reino" à "Fábula de Anfion", de João Cabral, enfatiza a difícil tarefa de comprovar ou refutar o nexo entre as obras. Para o crítico, ambos poemas mobilizam "antes de tudo, a imagem de um rei frente a um deserto", que enfrentam "a aridez e a esterilidade da terra" além de seus princípios poéticos, alcançando o dilema "ético-estético".

Menos em uma linha social e histórica que leva Sterzi (2011: 16), não equivocadamente, a comparar as imagens de um rei menos o reino à terra devastada e sua tradição literária, o poema também pode ser lido como um canto endereçado a um sujeito do afeto, quase com um apelo erótico.

Entretanto, há no poema a relação entre a difícil ação/enunciação e a própria tarefa do fazer poético. E ainda: o poema confunde-se entre duas coisas, numa espécie de apreensão da natureza e sua relação com aspectos do feminino (a concha, o mar, o vento, a Dulcamara, o sol, o corpo, a flor, a seda) e também uma natureza de forma asséptica (a pedra, a areia, o sol, o solo, a rocha, os corvos) e os anseios desse eu que fala e ouve, mas não fala e não ouve, que enfrenta a dureza da pedra, a escuridão do mar e o agora/ outrora em uma posse despossuída, até mesmo de seu próprio cantar.

Para Maciel (2004: 135) as duas paisagens que se justapõem e interseccionam são da aproximação desse "eu" e sua "paisagem intrínseca" e a configuração desértica de sua dimensão extrínseca, marcadas pela "errância" - a busca do eu poético por seu canto em um "lugar sem lugar". No entanto, se a areia é parte da pedra deste "duro reino", o oceano pode representar, para além do eu, o canto direcionado ao outro, por meio de um salto ao mar.

O poema apresenta em sua composição elementos marítimos e associados a uma Vênus que vem do mar, sugerindo a invocação à musa (aí está o canto) - que mesmo depois de morta é luz nas profundezas do oceano. Em relação metonímica, o eu poético se aproxima dos elementos que formam esse outro ("levo-me aos teus cabelos, não a ti" - "galgo o teu corpo - não a ti") que a leva até à morte - morte essa que pode ser entendida como o fazer poético, o gozo da experiência com a linguagem, mas que é ainda um "alvo" fechado contra si.

Em "Poetamenos", de 1955, Campos se apropriará do procedimento weberniano de klangfarbenmelodie (melodia de timbres), compondo seu poema em forma de partitura. Não muito distante, temporalmente, de "O rei menos o reino", o poema-partitura é direcionado a um sujeito de afeto. Aguilar (2005: 294) recorda que o poema apresenta uma "fusão do poeta com seu material e a mulher amada" - e, aqui, vem a palavra poeta também em razão de que o corpo ganha um nome - Lygia - esposa de Augusto. O horizonte da "imanência", segundo Aguilar, denota os signos opacos e os "próprios corpos" se transformando em signos que se fundem sexualmente. 
A fim de defender uma leitura que passa pela metamorfose, o crítico continua a olhar em "Poetamenos" aquilo que há de erótico e aquilo que apresenta uma incorporação de uma coisa pela outra. Para isso, ele cita a imagem da concha ("conchiglia") que aparece no poema e, ainda, relaciona a "perseguição" das cores pelas palavras como um "fauno a uma ninfa". Aguilar ainda retoma os estudos dos anagramas de Saussare, em que Lygia é Vênus 4 e relembra que, em "Poetamenos", como em "O rei menos o reino", há uma progressão de elementos de fusão que desembocam em uma encenação da "separação", da "ausência" e da "angústia". Assim, é possível notar uma aproximação entre esses dois poemas, que estão marcados pela ideia do canto, do teor erótico e do avanço para uma ideia de negação do dito.

Nas partes seguintes há uma chave que se vira em uma luz que se torna sombra e a presença da morte se faz uma qualidade nesta rainha, com quem o eu poético fala. O rei sem vassalos, como uma figura fragmentada diante do espelho "pisa o próprio corpo", experimenta a "angústia”, o "tédio", o “ódio", o "medo" diante de uma "rainha morta" enterrada em uma carta de baralho. "Nascido a sangue" como o caule de uma flor entre as pedras, em um desértico solo, suscetível aos desmandos do vento, o eu poético encontra e perde sua voz. Essa imagem repartida, paisagem do real/irreal, encontra também eco na poesia moderna, como a de Rimbaud. Demonstra Friedrich:

[...] "o rei, de pé, sobre sua barriga”; "muco azul”: estas imagens podem, sem dúvida, expressar, às vezes, as qualidades existentes nas próprias realidades com eficácia mais cortante, porém não tendem ao real: seguem uma dinâmica destrutiva que - em substituição ao "desconhecido" invisível - converte o real em um desconhecido sensivelmente excitado e excitante, removendo os limites de suas figuras, forçando os seus extremos a se unirem. (Friedrich 1991: 80)

Assim, na parte seis, o eu-poético se lança em "posição mortal" e escarnece sobre seu próprio nome em várias línguas, encontrando um mar de "peixes mudos" que sua voz ofende - eco explícito de Cabral: "A flauta, eu a joguei/aos peixes surdo-/mudos do mar". ${ }^{5}$ No mar frio, o canto se sufoca ainda mais, o "ar é mais escasso", mas "confirmado os olhos" para não perder a luzes, deixa um "rasto do seu brilho".

A luz aqui pode ser indicada pela relação do eu poético com a rainha, assim como com sua tentativa de canto. A paisagem de um sol sem brilho, que aparece na segunda parte, se contrapõe a um "rosto mais claro que o ouro" (parte três) e volta na parte seis como "as duas luzes" que poeta deseja não perder:

Antes, porém, cuidei de ter confirmados os olhos

Para que as pálpebras não ocultassem nunca

As duas luzes

(Campos 1986: 14) 
Fechando o poema, o último canto dirige-se a um "povo meu ó polvo" que deixa "um rasto sempre o mesmo, negro" - desprovido de luz. O eu poético pergunta ao povo/ polvo, com seus variados tentáculos, que "queres mais de mim além de mim?". Ora, arrancada a língua e com a hera cobrindo as palavras, o que resta cantar? Ou, diante da morte e da afasia, ${ }^{6}$ sem ter a iluminação daquela para quem canta e mergulhado num mar surdo, como cantar?

Na última oferta, a derradeira empreitada em que aparecem os versos finais, a imagem da pedra volta como algo que se retira da fala. Seria a palavra pedra, marcada em diversos momentos, um sinônimo da palavra "não"? É possível voltar todo o poema substituindo "pedra" por "não" e, ainda, alcançar fora da criação da imagem do deserto, um mesmo deserto - agora da linguagem. O canto capaz de criar um reino como Fábula é, ao mesmo tempo, incapaz. Não só a terra é dura como pedra, mas também a palavra poética. Um canto que é não canto, os ouvidos moucos, a rainha morta e enterrada, a poesia que nasce já sufocada pela aridez-arena e a forma da pedra.

Quando começo: - Mar... - os teus ouvidos apodrecem

(Não se comove a tua massa, move apenas

Aquelas negras, negras vozes,

Falam em pão em prata e eu ouço: PEDRA).

(Campos 1986: 15)

O destinatário, embora de grande relevância para o poema, uma vez que há uma tentativa de uma comunicação com ele, se mostra como algo que é e pode ser. A referência a Cabral, antes mesmo de ser dada pela contemporaneidade dos escritores e, posteriormente, às diversas menções que Augusto faz a ele, seja na construção do Paideuma concreto, seja no poema ("João/agrestes") que fará anos depois, permite-nos ler a imagem desértica e da obsessão pela pedra como um reflexo de Cabral em sua obra.

É interessante notar ainda que Sterzi, para analisar Cabral, retoma Valéry, por também insuspeita influência desse no outro - que o crítico apresenta, de maneira exemplar -, assim como faz com Campos e, como consequentemente, fazemos aqui. Com isso, quero salientar esse papel da crítica que procura, cavoucando a pedra, o ar que se "move de outras vozes". Embora o índice esteja marcado nos contornos do texto literário, de sua composição semântica às noções de biografia e contato entre autores, "todo pensamento emite um lance de dados".

Pode-se entender que a poesia moderna - mesmo a dita antipoética - apresenta traços propositivos. Longe de querer superar o vício dos dados, os poetas acabam por tirar proveito das mesmas imagens para dar continuidade ao jogo, tensionando (nov)os signos e mesclando as vozes em um canto - que como os outros - é anticanto. Em "O rei 
menos o reino" há um universo de relações que se misturam pelo uso dos grandes temas e nas vozes da tradição. Como demostra Friedrich:

A poesia quer ser, ao contrário, uma criação autossuficiente, pluriforme na significação, consistindo em um entrelaçamento de tensões de forças absolutas, as quais agem sugestivamente em estratos pré-relacionais, mas também deslocam em vibrações as zonas de mistério dos conceitos. (Friedrich 1991: 16)

Assim, nota-se que mesmo que o deserto e a pedra de Cabral sejam, de maneira irrefutável, caminhos para a leitura do poema, ainda é possível propor uma leitura pelas vias do canto direcionado (também possível eco de Cabral), tentativa de diálogo com um sujeito amado, mas também com a tradição da modernidade poética, de maneira geral.

Convém mencionar que mesmo que a leitura dos poemas de Augusto (e da poesia, de modo geral) possa e deva ser ampliada no campo histórico, uma vez que isso enriquece a busca por significados dentro do poema, essa é uma tarefa que funciona como um caminho para a crítica, que almeja descortinar o poema a fim de ver "o diante e o dentro" - tomando aqui de empréstimo a expressão de Georges Didi-Huberman (2014: 231).

\section{Voltas ao redor do não}

Augusto de Campos sempre se apresentou como poeta, primeiramente. Isso pode ser visto nas diversas entrevistas que o poeta deu ao longo da vida e em algum de seus prefácios, textos ensaísticos e traduções. O estatuto - de antes de tudo, poeta - pode vir de uma tomada de posição política frente ao campo literário e a multiplicação das críticas direcionadas ao movimento da poesia concreta. Em prefácio para o livro Outro, de 2015, seu último livro publicado com uma grande editora (o poeta também tem publicado traduções em forma de plaquette, pelo selo Galileu Edições) Augusto de Campos afirma: "faço poesia porque não sei fazer outra coisa".

A poesia de Campos, via para um caminho "sem saída", ${ }^{8}$ enquanto tarefa e/ou destino, encontrou no mar das vaias e dos "tempos de pobreza" as mais variadas formas de se materializar. Para Siscar (2006: 127), entre os poetas concretos, Augusto foi o que mais experimentou poéticas baseadas em recursos técnicos ligados à "visualidade, à sonorização, à espacialização, ao cruzamento de mídias, acompanhando as possibilidades instrumentais que iam se abrindo com as novas máquinas produtoras de representação".

O poeta foi considerado, tanto por Philadelpho Menezes, teórico da poesia concreta e visual, quanto por Gonzalo Aguilar, que também se dedicou a escrever sobre a poesia do grupo Noigandres, como o mais ortodoxo dentre eles, com uma poética que se manteve mais distante da cultura de massas, mas que também sempre seguiu um rigor formal. Embora a obra de Campos tenha se modificado com o tempo, pautada na experimentação gráfica e digital, ela sempre contou com a verbivocovisualidade como práxis estética, desde o princípio dos contornos de um movimento internacional, junto a Eugen Gomringer, em 1955. 
Augusto de Campos dedicou parte da sua obra traduzindo poemas e textos de autores que foram negligenciados tanto nos cânones de seus países quanto pela crítica brasileira, colocando-os em um espectro da marginalização da "estrada oficial das letras". Suas obras mais importantes sobre o tema são o livro de ensaios e traduções Poesia de Recusa, de 2011, e o de igual gênero A margem da margem, de 1989.

Há nessas obras uma espécie de crítica contra o cânone, favorecendo uma visada sincrônica sobre a história da literatura. Em uma tentativa também de reafirmar a importância do movimento da poesia concreta para o campo literário brasileiro, o poeta dedica-se a dar valor àquilo que estava margem. A recusa será marcada em toda a obra poética de Campos, visível no título de seus livros, tais como Não - poemas, de 2003, Despoesia, de 1994, Expoemas, de 1985, Poetamenos, de 1953, e em inúmeros poemas dentro desses livros (e em outros) que marcam a recusa, a negação, o "estar à margem", o "ser contra o sistema".

Em introdução à Poesia de Recusa, Campos escreve:

Não há concessões. Não há apelações. A poesia requer de nós algum instinto revolucionário, sem o qual ela não tem sentido. Os textos escolhidos manifestam, implícita ou explicitamente, formas de desacordo com a sociedade ou com a vida, capazes - eu suponho - de despertar esse ímpeto revolucionário nos leitores e fazer com que as vivências se enriqueçam com a sofrida experiência da recusa poética. (Campos 2011: 17)

No texto introdutório de $A$ margem da margem, Campos se manifesta mais uma vez contra os órgãos e agentes legitimadores da dita boa literatura, revelando também seu percurso pela margem. Se o caminho da estrada oficial das artes é essa cruzada impossível, ao poeta cabe promover "imprevistos, desvios arriscados dentro do percurso", a fim de fazer transitar sua poética nas vias paralelas, insubordinadas, revolucionárias. Nesse sentido, a prática da autopublicação se tornou uma forma de reagir a um "não exterior" que encontra eco em um "não interior". A autopublicação como desvio se mostrava uma alternativa aos sons mais "acomodatícios e mais digeríveis" da literatura, abrindo espaço em um campo literário resistente, para uma poesia da recusa (Campos 1989: 9).

Sobre as formas do não na construção poética, convém mencionar que, como sugeriu Luiz Costa Lima (2004: 116), há na língua portuguesa duas modalidades negativas: "o não, simplesmente negador e o não afirmativo". O não afirmativo apareceria na língua como partícula de reiteração do sim, pela negação do seu contrário. Mas o que Costa Lima procura mostrar, mais precisamente, é o uso do "não afirmativo", na poesia de Campos, enquanto um programa das "práticas propulsoras do poiético", materializada em tradução (transcriação) e na produção de poesia.

Para Costa Lima (2004: 119), o não afirmativo, na poesia de Augusto de Campos, opera por um repúdio ao fácil, "propondo em seu lugar a energia criadora do código verbal”. Campos também materializa o não em sua obra, como já mostrou Sterzi (2006: 
22) tanto pelas operações do mínimo múltiplo comum ${ }^{10}$ na linguagem (poemas de uma palavra só, poemas com pouquíssimas palavras, poemas sem palavras, poemas muito tensionados, como "sos", "poema-bomba", "tensão", "vida" - e tantos outros) quanto pelo uso de expressões de negação "não", "nada”, "menos", "silêncio”, "des-", "ex-".

Um "pequeno exemplo" de uma forma da prática da recusa na obra de Augusto de Campos é o livro-xerox Não, um livreto de dimensões 4,4 x 4,5, de 1990. Sobre o livro, o autor comenta em entrevista:

[...] Queria expressar a minha mágoa pela morte prematura do Omar Guedes, querido amigo e parceiro de Expoemas (1985), que morreu de leucemia, de maneira fulminante. Tínhamos feito edição que ele realizou maravilhosamente, como grande artista da serigrafia que era. Ele fez ainda algumas lindas serigrafias, em dimensão maior, de Profilograma DP, PósTudo, Renovar, além de vários postais serigráficos. Colaborou também na confecção das serigrafias para os meus hologramas. Planejávamos um novo álbum com Intraduções e Profilogramas, quando a morte o colheu abruptamente. Fiquei muito triste. Quis protestar usando o material mais pobre e de menor tamanho que me era possível utilizar. Não vendi, só distribui entre amigos os exemplares hipoteticamente numerados de 0 ao $\infty$. (Mattar 2019: 7)

No relato, Augusto de Campos demonstra sua preocupação com o aspecto material do livro para que fosse algo de ínfimo valor e importância, contrapondo-o a algo majestoso - a edição de Guedes, em formato ampliado de cartaz. Ironicamente, por ter sido distribuído apenas aos seus pares, o livro, hoje, é considerado raridade, assim como Expoemas, de 1985, embora um se realize na arte povera e o outro dialogue mais com o livre d'artiste ou livre de luxe.

O tema da recusa é explícito logo na capa do livro, dialogando com o programa de vida/obra de Campos. O poema marca a recusa à própria poesia, mas não deve ser visto de forma ingênua: é a recusa ao que é dado como poesia, assim como pode ser um reflexo de anos de negação da legitimação da poesia concreta (e a sua própria) e de sua importância. Além disso, o poema se comunica na via dupla da negação, afinal, trata-se de um poeta que recusa a poesia pela própria via do poema. Afinal, o que quer dizer Campos (2015: 1) quando afirma, em prefácio ao livro de poemas Outro: “eu também não gosto de poesia"?

A edição xerox em Não confirma essa recusa, uma vez que sua materialidade apresenta uma certa precariedade. Embora, o poeta não tenha, de fato, pensado no uso do xerox ${ }^{11}$ como uma ligação do suporte com a poesia marginal, não podemos negar a noção de autonomia que o uso do xerox tem na prática de autopublicação, comunicando a resistência a se vender a um grande mercado.

O poema em formato de quadrícula se mostra a partir da aglutinação entre as letras, formando palavras. Costa Lima (2004: 123) entenderá as letras como dígitos, em sua função de pontos. Neste caso, o poema conta com dez pontos horizontais e cinco pontos 
verticais, como coluna vertebral que sustenta a forma. Pela via da supressão, Campos vai retirando as colunas, diminuindo as possibilidades da "poesia" (ou "oesia", obedecendo os cinco pontos, que denota sua função de "resto" da tarefa do poético).

A construção negativa conduz a leitura, através da proposição "quer que seja $x, x$ ainda não é poesia". A tentativa de definir a poesia se dá pela subtração, uma vez que as linhas vão perdendo pontos e, consequentemente, a composição de palavras vai se abreviando. Mesmo no início do poema, onde se encontra a quadrícula que propõe o jogo, "ainda que a base semântica seja evidente, semanticamente, considerados os enunciados são, para a poesia, irrelevantes" (Costa Lima 2004: 123).

A progressão do poema se plasma ao seu ritmo e estrutura, dando a ideia de que a captura da poesia, além de tarefa impossível que leva ao desfiladeiro (nota-se pela forma do último "verso"), só pode ser feita a partir do movimento de ir ao encontro a, ao mesmo tempo que vai ao encontro de (um colidouescapo). ${ }^{12}$

As formas adversativas "ainda", "não", "quase" que aparecem no poema em momentos diversos ou pontuais levam ao beco sem saída: tudo que pode ser poesia ou tudo que a poesia pode ser é "ainda"- não ou "não"- algo, é quase poesia. O silêncio da produção do poeta nos anos seguintes, que o faz afirmar "eu também não gosto de poesia", pode ser visto como um "gesto-não", paradoxal à zona de "sim" que o leva a continuar experimentando em linguagem, mesmo que seja para negá-la. Um não como sim, como sugeriu Costa Lima (2004: 116).

A noção de intenção aqui é importante para pensar nos aspectos materiais do poema. Como relatou Campos, o uso do xerox, do formato mínimo e da simplicidade na composição fazem alusão a uma tentativa de homenagem a Guedes. 0 design visual, ou forma estrutural do poema, também parecem materializar a perda: o poema vai perdendo seus significados, na medida que o material fonético vai sendo subtraído e se transformando (afinal, não se trata simplesmente de um texto que se apaga, mas de mobilização de um campo semântico relativo à tarefa da própria poesia que leva a seu "consumo") naquilo que sucede em seu despojamento.

\section{Considerações finais}

Seja pela ausência da voz, seja pela ausência de material fonético, o "não" aparecerá na obra de Augusto de Campos como espinha dorsal do fazer poético. A obsessão pelo quase dito ou pelo não dito pode ser tomada sempre por sua fórmula "menos", pelas imagens da negação e da subtração, tirando da linguagem aquilo é próprio a ela: sua inviabilidade.

Considerando o fazer poético como um jogo, o poeta usa os elementos de composição do signo - seus aspectos semânticos, sonoros e visuais - a partir dos elementos materiais que tem à mão. Analisando sistematicamente um poema em versos, como "O rei menos o reino", e um poema de estrutura comunicante, como "Não", vemos as transformações de uma poética potente. As voltas ao redor do signo da pedra já prenunciavam a busca 
por uma negatividade da linguagem que desembocará nas formas radicais da poesia de Augusto de Campos.

A transição de uma coisa à outra mostra esse percurso do poeta, passando sempre por paisagens, imagens e formas da negação que encontram, na experimentação em linguagem e na materialidade poética, formas de se reinventar. Neste sentido, o que sairá daí ainda são possíveis leituras de uma poesia que está sempre no porvir. Nas palavras do poeta: "Sobrevivente, para o bem ou para mal, não posso deixar de completar o que comecei, o quanto me for possível" (Campos 2015: s/p).

\section{NOTAS}

* Marina Ribeiro Mattar é formada em Licenciatura em Letras pela Universidade Estadual Paulista (Unesp), mestra em Estudos de Linguagens pelo Centro Federal de Educação Tecnológica de Minas Gerais e doutoranda em Estudos Literários na Universidade Federal de Minas Gerais. Pesquisa sobre a poesia concreta e suas relações com o livro de artista e as artes visuais.

${ }^{1}$ AD AUGUSTUM PER ANGUSTA título e verso final de um poema de Augusto de Campos, remetia ao leitor à etimologia latina do termo angústia, derivado de angustus, estreito". Na língua portuguesa, é a palavra que indica "passagem estreita entre ribanceiras, o que chamamos também de desfiladeiro". CONDE, Miguel. Pela via "augusta" do poema e da política. Suplemento Pernambuco, maio (2019: 12).

${ }^{2}$ Correspondendo à fase chamada pré concreta.

${ }^{3}$ Tomando de empréstimo o uso do termo cunhado por Ezra Pound, em ABC da Literatura, que se refere à composição semântica, no poema.

${ }^{4}$ Ver Aguilar, Gonzalo (2005), Poesia concreta brasileira: as vanguardas na encruzilhada modernista. Edusp, São Paulo: 294.

${ }^{5}$ Melo Neto (1947), João Cabral de, Psicologia da composição com a Fábula de Anfion e Antiode, Barcelona: 0 Livro Inconsútil. Edição de autor, Barcelona.

${ }^{6}$ Em 1996, José Américo Miranda chamou o poema de "cantiga de um trovador afásico", no artigo "Dias dias dias: um poema de Augusto de Campos”, para a revista Contexto, ano v, n.4.

${ }^{7}$ Mallarmé, Stéphane (2002), Um lance de dados jamais abolirá o acaso. Tradução Haroldo de Campos. Perspectiva, São Paulo.

${ }^{8}$ Poema de 1999, de mesmo título. Disponível em flash no site do poeta: http://www.augustodecampos.com. br/semsaida.htm 


\footnotetext{
${ }^{9}$ Sobre o "mar de vaias", refiro-me à citação de Jean Cocteau na epígrafe da antologia poética VIVAVAIA: "aquilo que o público vaia,/Cultive-o,/é você". Sobre "tempos de pobreza", refiro-me à epígrafe de Hölderlin, em O rei menos o reino, "...e para que poetas em tempo de pobreza?".

10 "A poesia concreta visa ao mínimo múltiplo comum da linguagem" - Campos, Augusto de; Pignatari, Décio; Campos, Haroldo de (1975), "Plano-piloto para poesia concreta", in Teoria da poesia concreta: textos críticos e manifestos 1950-1960. Duas cidades, São Paulo: 157.

${ }^{11}$ Em entrevista à pesquisadora, Campos declara: "Não pensei na arte xerox" e atribui a escolha do suporte a uma forma de protesto à morte prematura de Omar Guedes (Mattar 2019: 7).

${ }^{12}$ Collideorscape é uma palavra-valise que aparece em Finnegans Wake, de James Joyce (1939). Em 1971, Augusto de Campos compõe Colidouescapo, um livro de páginas soltas, reeditado em 2006, pelo selo Demônio Negro.
}

\section{BIBLIOGRAFIA}

Aguilar, Gonzalo (2005), Poesia concreta brasileira: as vanguardas na encruzilhada modernista. São Paulo, EDUSP.

Campos, Augusto de (1973), Poetamenos (1953 - 1973). São Paulo, Edições Invenção.

-- (1986), VIVAVAIA: poesia 1949-1979, São Paulo, Ed. Brasiliense.

-- (1989), A margem da margem. São Paulo, Companhia das Letras.

-- (1990), Não. São Paulo, edição de autor.

-- (2006), Poesia da recusa. São Paulo, Perspectiva.

-- (2006), Colidouescapo. São Paulo, Demônio Negro.

-- (2015), Outro. São Paulo, Perspectiva.

Campos, Augusto de/ Pignatari, Décio/ Campos, Haroldo de (2006), Teoria da poesia concreta: textos críticos e manifestos. Cotia, Ateliê.

Campos, Haroldo de (1982), Arte pobre, tempo de pobreza, poesia menos. São Paulo, Novos Estudos Cebrap, v. 1, n. 3, 63-67.

Conde, Miguel (2019), "Pela via "augusta" do poema e da política". Suplemento Pernambuco, maio, 12-15.

Didi-Huberman, Georges (1998), O que vemos, o que nos olha. São Paulo, Ed. 34.

Friedrich, Hugo (1991), Estrutura da Lírica Moderna. São Paulo, Livraria Duas Cidades.

Lima, Luiz Costa (2004), "Duas aproximações ao não como sim”, in Süssekind, Flora/

Guimarães, Júlio Castañon (org.) (2004), Sobre Augusto de Campos. Rio de Janeiro, 7Letras: Fundação Casa de Rui Barbosa. 
Maciel, Maria Esther (2004), "De pedra e areia”, in Süssekind, Flora/ Guimarães, Júlio Castañon (org.) (2004), Sobre Augusto de Campos. Rio de Janeiro, 7Letras: Fundação Casa de Rui Barbosa.

Mallarmé, Stéphane (2002), Um lance de dados jamais abolirá o acaso, tradução de Haroldo de Campos, Perspectiva, São Paulo.

Mattar, Marina Ribeiro (2019), De 0 ao $\infty$ : entrevista com Augusto de Campos. Alecrim, Belo Horizonte.

Melo Neto, João Cabral de (1947), Psicologia da composição com a Fábula de Anfion e Antiode. Barcelona, O Livro Inconsútil. Edição de autor: Barcelona.

Pound, Ezra. ABC da literatura (2006), Cultrix: Tradução de José Paulo Paes e Augusto de Campos. São Paulo.

Siscar, Marcos (2006), "A crise do livro ou a poesia como antecipação", in Sterzi, Eduardo (org.), Do céu do futuro: cinco ensaios sobre Augusto de Campos. São Paulo, Marco: 115-135.

Sterzi, Eduardo (org.) (2006), Do céu do futuro: cinco ensaios sobre Augusto de Campos. São Paulo, Marco.

-- (2011), "O reino e o deserto: a inquietante medievalidade do moderno". Boletim de pesquisa Nelic. Florianópolis, edição especial v. 4, <https://periodicos.ufsc.br/index. php/nelic/article/view/1984-784X.2011nesp4p4> (último acesso em: 15/01/2021).

Süssekind, Flora/ Guimarães, Júlio Castañon (org.) (2004), Sobre Augusto de Campos. Rio de Janeiro, 7Letras: Fundação Casa de Rui Barbosa. 